\title{
Elastin-derived peptides are involved in the processes of human temporomandibular disorder by inducing inflammatory responses in synovial cells
}

\author{
KAZUHIKO KOBAYASHI ${ }^{1}$, REI JOKAJI ${ }^{1}$, MAYUKO MIYAZAWA-HIRA ${ }^{1}$, SHIGEYUKI TAKATSUKA ${ }^{2}$, \\ AKIRA TANAKA $^{1}$, KAZUHIRO OOI $^{1}$, HIROYUKI NAKAMURA ${ }^{1}$ and SHUICHI KAWASHIRI ${ }^{1}$ \\ ${ }^{1}$ Department of Oral and Maxillofacial Surgery, Kanazawa University Graduate School of Medical Science, \\ Kanazawa, Ishikawa 920-8640; ${ }^{2}$ Department of Oral and Maxillofacial Surgery, Public \\ Central Hospital of Matto Ishikawa, Hakusan, Ishikawa 924-8588, Japan
}

Received August 24, 2016; Accepted May 30, 2017

DOI: $10.3892 / \mathrm{mmr} .2017 .7012$

\begin{abstract}
Temporomandibular joint dysfunction (TMD) is a collection of clinical symptoms that involve masticatory muscles and the temporomandibular joint (TMJ). Common symptoms include limited jaw motion and joint sound/pain, along with TMJ disc displacement. TMD is frequently associated with synovitis, a chronic inflammation of the synovium. Fibroblast-like synovial cells have been identified to produce several inflammatory mediators and may have an important role in the progression of TMJ inflammation. Degradation of the extracellular matrix molecule elastin may lead to the release of bioactive peptides. The present study aimed to explore the role of elastin-derived peptides (EDPs) in human temporomandibular disorders. Therefore, interleukin-6 (IL-6) expression in the synovial fluid obtained from patients with TMD correlated significantly with two clinical parameters, specifically TMJ locking and pain/jaw function on a visual analog scale (VAS). To the best of our knowledge, this is the first study to determine that the concentration of EDPs in synovial fluid from patients with TMD may also be significantly correlated with the duration of TMJ locking, the VAS score and IL-6 expression. In vitro, EDPs act on human TMJ synovial cells to promote upregulation of IL-6 and the elastin-degrading enzyme matrix metalloproteinase-12
\end{abstract}

Correspondence to: Dr Hiroyuki Nakamura, Department of Oral and Maxillofacial Surgery, Kanazawa University Graduate School of Medical Science, 13-1 Takara-machi, Kanazawa, Ishikawa 920-8640, Japan

E-mail:hnak@me.com

Abbreviations: TMJ, temporomandibular joint; EDPs, elastinderived peptides; TMD, temporomandibular dysfunction; EBP, elastin binding protein; VAS, visual analog scale; ELISA, enzymelinked immunosorbent assay; OA, osteoarthritis; ADD, anterior disc displacement

Key words: elastin-derived peptides, inflammatory responses, MMP-12, elastin binding protein, temporomandibular disorders
(MMP-12). The upregulation of IL-6 and MMP-12 expression by EDPs may be mediated through elastin-binding proteins (EBP) and a protein kinase A signalling cascade. These findings suggest a model for inflammation in the TMJ where EDPs are generated by harmful mechanical stimuli, induce both a pro-inflammatory cascade and increase expression of MMP-12 through activation of the EBP signalling cascade. This may lead to further increases in EDP levels, establishing a positive feedback loop leading to chronic inflammation in the TMJ. Therefore, significantly elevated levels of EDPs and IL-6 in the synovial fluid of the TMJ may be indicators of the pathological conditions of the joint.

\section{Introduction}

Temporomandibular joint dysfunction (TMD) is a collective term describing a range of clinical symptoms that involve the muscles of mastication and the temporomandibular joint (TMJ), which is a bilateral synovial joint formed from the upper temporal bone of the skull and lower jawbone (mandible). TMD is characterized by restricted jaw motion and joint sound and pain and often includes TMJ disc displacement, internal derangement, and osteoarthritis (OA). In TMD, synovitis that often accompanies intra-capsular pathologic conditions is characterized by chronic inflammatory changes (1-3). The synovial membrane that covers the inner wall of the TMJ capsule is populated by fibroblast-like stromal cells and lining cells. Fibroblast-like cells have an important role in the progression of inflammation in the TMJ due to their ability to produce a number of pro-inflammatory mediators (4-6). The process by which TMJ synovitis is initiated and maintained remains to be elucidated; however, several pro-inflammatory cytokines, such as tumour necrosis factor (TNF- $\alpha$ ), interleukin (IL)- $1 \beta$, IL-6, IL-8 and interferon $\gamma$ (IFN $\gamma$ ) have been detected in either synovial fluid (7-13) or in synovial tissue (5) obtained from patients with internal derangement of the TMJ or OA of the TMJ. Therefore, these cytokines may be involved in the pathophysiology of TMJ internal derangement and OA.

Elastin is an extracellular matrix molecule responsible for the mechanical resilience of tissues and was initially believed 
to be restricted to this role (14). In keeping with its important structural role, elastin has a very long half-life. However, elastin turnover is dramatically accelerated in various disease states including arthritis, atherosclerosis, emphysema and cancer (15). Elastin degradation leads to the production of bioactive peptides termed elastin-derived peptides (EDPs) (16). The hexapeptide VGVAPG, which may be detected in insoluble elastin and EDPs, may responsible for bioactivity as it may bind to the elastin receptor and exert numerous biological effects, including atherosclerosis (17). Although several other receptors have been suggested to bind EDPs $\left(\alpha_{v} \beta_{3}\right.$ and $\alpha_{v} \beta_{5}$ integrins, galectin-3), the principal EDPs receptor remains the elastin receptor complex (18). This heterotrimer is composed of a peripheral subunit, termed the elastin binding protein (EBP), associated with the protective protein/cathepsin A. The latter is bound to a membrane-associated protein termed neuraminidase-1. Specific interactions between inflammatory cells and EDPs previously established (19).

Anatomically, the TMJ disc is attached to the capsule and its surrounding structures (20). In humans TMJ disc elastin is abundant in both the anterior and posterior attachment structures, particularly thick elastic fibres are located in the upper bilaminar zone (21). It is of note that, as a consequence of aging, there is a reduction in the number of elastic fibres in the TMJ disc (22-24). However, the absence of mastication movements in foetuses and new-borns correlates with the presence of abundant elastic fibres in all areas of the TMJ disc (24). In adults with teeth, as well as edentulous older people, elastic fibre density has been identified to be considerably reduced in the middle of the bilaminar intermediate zone (25). It is likely that mechanical factors, particularly pressure created during mastication, may explain this phenomenon. Previous studies on diseased human TMJ discs have revealed a significant reduction in the number of elastic fibres in the bilaminar zone $(23,26,27)$.

At present, there is minimal information regarding the involvement of elastin degradation in the processes of synovitis in human TMD. The present study aimed to investigate the importance of EDPs in human TMD. To the best of our knowledge, the present study was the first to reveal that EDPs in synovial fluid of patients with TMD were correlated with the duration of TMJ locking and VAS score, and that EDPs induce inflammatory responses in human TMJ synovial cells. This important finding indicates that elastin degradation is an event that may be involved in the establishment of human TMD.

\section{Materials and methods}

Human samples. Experiments using human samples were approved by the Ethics Committee of the Kanazawa University Graduate School of Medical Science (IRB no. 2014-005, 351-2), and written informed consent was obtained from patients providing the specimens. Patients were diagnosed with closed lock disc disease in the temporomandibular joint and were treated using pumping manipulation at Kanazawa University Hospital (Kanazawa, Japan) between April 1997 and March 2000. Synovial fluid was obtained from the TMJ of 28 patients. The patients ranged between 16 and 66 years of age $(38.3 \pm 17.7$ years old, mean \pm SD), and 25 patients $(89 \%)$ were female. Samples were collected from the TMJ using a push and pull technique, as previously described (28). Clinical examinations were performed prior to synovial fluid collection. They included recordings of maximum incisal opening, pain upon incisal opening, pain upon palpation of muscles and the TMJ, subjective reports on pain and function of the jaw, using a visual analogue scale (VAS), and the duration of locking disc disease.

Cell culture. Human synovial fibroblast cells were prepared from TMJ synovial tissues obtained at arthroplasty from 1 patient with TMJ ankyloses (68 years old male) and 2 patients with condylar fracture of the mandible (23-year-old female and 43-year-old male). These 3 patients underwent surgery at Kanazawa University Hospital between April 1997 and March 2000. Tissue samples were treated with 5\% bacterial collagenase type I (Worthington Biochemical Corporation, Freehold, NJ, USA) for $1 \mathrm{~h}$ at $37^{\circ} \mathrm{C}$ and $0.02 \%$ trypsin (Thermo Fisher Scientific, Inc., Waltham, MA, USA) for $30 \mathrm{~min}$ at $37^{\circ} \mathrm{C}$. After the activities of these proteinases were blocked with $10 \%$ foetal bovine serum (FBS; GE Healthcare, Logan, UT, USA), the $1 \times 10^{5}$ cells were seeded in culture dishes and maintained in Dulbecco's modified Eagle's medium (DMEM; Sigma-Aldrich; Merck Millipore, Darmstadt, Germany) containing $10 \% \mathrm{FBS}$ at $37^{\circ} \mathrm{C}$ in a humidified $5 \% \mathrm{CO}_{2}$ atmosphere. Human lung elastin peptides were purchased from Elastin Products Company (Owensville, MO, USA) (29). Cells below passages 3-6 were used in the subsequent experiments. Prior to EDP treatment, cells were pre-incubated at $37^{\circ} \mathrm{C}$ for $12 \mathrm{~h}$ in serum-free DMEM medium and then incubated at $37^{\circ} \mathrm{C}$ for $24 \mathrm{~h}$ in DMEM containing $2 \%$ FBS and EDP (Elastin Products Company) at various concentrations $(0,25$, and $50 \mu \mathrm{g} / \mathrm{ml})$. For the in vitro inhibition studies, cells were pre-incubated for $12 \mathrm{~h}$ in serum-free DMEM medium with or without the protein kinase A (PKA) inhibitor N-[2-((p-bromocinnamyl) amino)ethyl]-5-isoquinolinesulfonamide (H89; $2 \mu \mathrm{M}$; LKT Laboratories, Inc., St. Paul, MN, USA) or $\beta$-lactose (20 mM; Santa Cruz Biotechnology, Inc., Dallas, TX, USA) or vehicle control (PBS only), and then incubated at $37^{\circ} \mathrm{C}$ for $24 \mathrm{~h}$ in DMEM containing $2 \% \mathrm{FBS}$ and with or without $50 \mu \mathrm{g} / \mathrm{ml}$ EDPs.

Enzyme-linked immunosorbent assay (ELISA). Human TMJ synovial fluid and supernatants, following 5 min centrifugation at $12,500 \mathrm{x} \mathrm{g}$ and $4^{\circ} \mathrm{C}$, obtained from cultured primary TMJ synovial cells were analysed for the presence of EDPs, IL-1 $\beta$, IL-6, TNF- $\alpha$ and matrix metalloproteinase-12 (MMP-12) using the appropriate ELISA kit (EDPs, cat. no. SK00806-01; Aviscera Bioscience Inc., Santa Clara, CA, USA; IL-1 $\beta$, cat. no. DLB50; IL-6, cat. no. D6050; TNF- $\alpha$, cat. no. DTA00C; all from R\&D Systems, Inc., Minneapolis, MN, USA; MMP-12, cat. no. EK0950; Boster Biological Technology, Pleasanton, CA, USA) according to the manufacturer's protocols. Total protein concentrations in the synovial fluid were determined by the dye binding method using an acidic solution of Coomassie Brilliant Blue G-250 dye, according to the manufacturer's protocol (Bio-Rad Laboratories, Inc., Hercules, CA, USA). Values were calculated as $\mathrm{pg} / \mathrm{mg}$ total protein or $\mathrm{ng} / \mathrm{mg}$ total protein. Data are presented as the mean \pm standard error of the mean. 
A

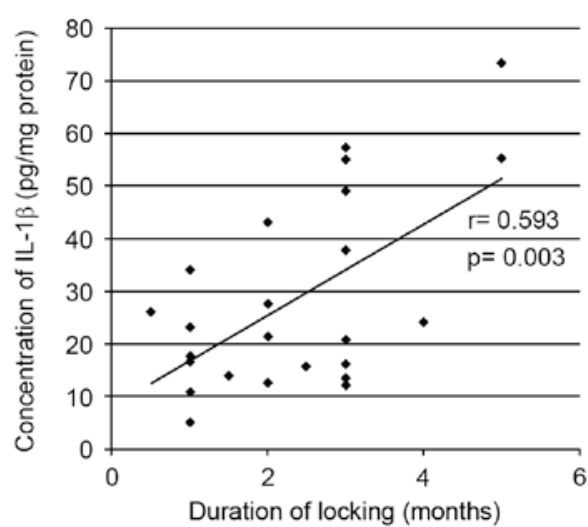

$\mathrm{C}$

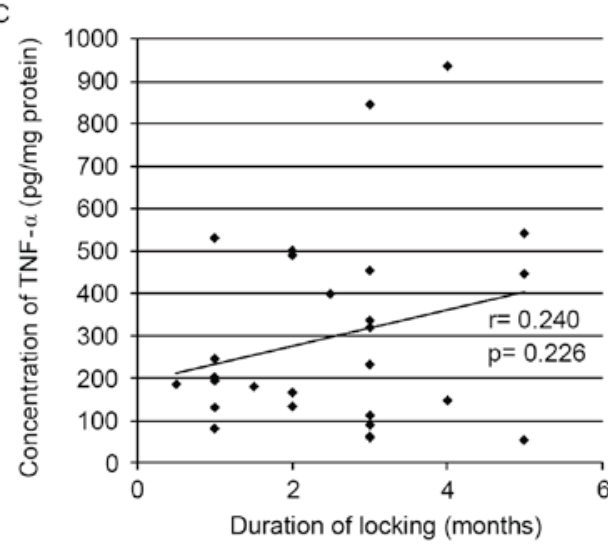

$E$

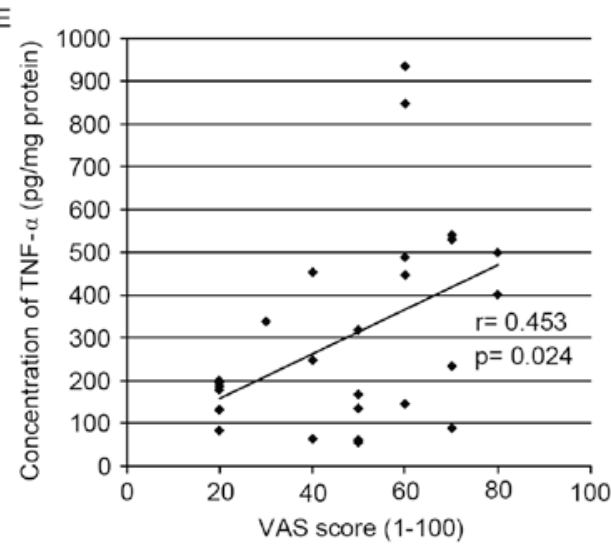

B
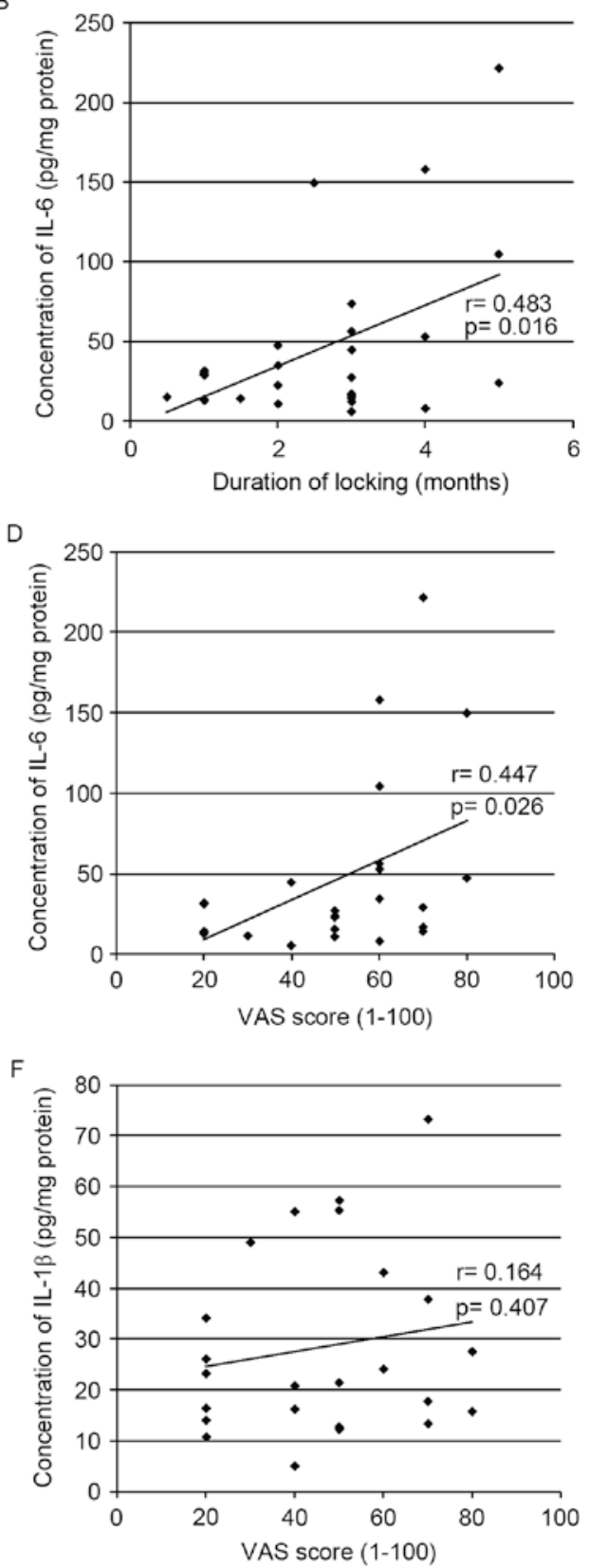

Figure 1. IL-1 $\beta$, IL-6 and TNF- $\alpha$ protein expression in synovial fluid from patients with TMD and their correlation with duration of TMJ disc locking duration or VAS score. The duration of TMJ disc locking for each patient was plotted against the respective (A) IL-1 $\beta$, (B) IL-6 or (C) TNF- $\alpha$ protein levels in synovial fluid. The VAS score for each patient was plotted against the respective (D) IL-1 $\beta$, (E) IL-6 or (F) TNF- $\alpha$ protein levels in synovial fluid. Each protein level represents the mean of three independent experiments. IL-1 $\beta$, interleukin-1 $\beta$; IL-6, interleukin-6; TNF- $\alpha$, tumor necrosis factor- $\alpha$; TMD, temporomandibular dysfunction; TMJ, temporomandibular joint; VAS, visual analogue scale.

Statistical analysis. For comparisons between samples, data was analysed by with analysis of variance and Tukey's multiple comparison test using SPSS version 23 (IBM Corporation, Armonk, NY, USA). $\mathrm{P}<0.05$ was considered to indicate a statistically significant difference.

\section{Results}

Concentrations of $I L-1 \beta, I L-6$ and TNF- $\alpha$ in the synovial fluid of patients with TMD are correlated with the duration of TMJ disk locking or VAS score. The concentration of IL-1 $\beta$, IL-6 and TNF- $\alpha$ in the synovial fluid of patients with TMD was quantified using ELISA and the correlation between the levels of these proteins and two clinical parameters was determined. The duration of TMJ locking had a positive correlation with IL-1 $\beta(r=0.593 ; P=0.003$; Fig. 1A) and IL-6 levels $(r=0.483$; $\mathrm{P}=0.016$; Fig. 1B); however, no correlation was identified with TNF- $\alpha$ levels $(r=0.240 ; P=0.226$; Fig. $1 C)$. In contrast, the VAS score had a positive correlation with IL-6 ( $\mathrm{r}=0.447$; $\mathrm{P}=0.026$; Fig. 1D) and TNF- $\alpha(r=0.453 ; \mathrm{P}=0.024$; Fig. 1E); however, no correlation was identified with IL-1 $\beta$ levels $(\mathrm{r}=0.164 ; \mathrm{P}=0.407$; Fig. 1F).

Concentration of EDPs in the synovial fluid of patients with TMD and correlation with duration of TMJ disk locking or the VAS score. The total concentration of EDPs in the synovial 
fluid of patients with TMD was measured and the correlation between the EDP levels and the clinical parameters was determined. The locking duration of TMJ had a positive correlation with EDP levels ( $r=0.750 ; \mathrm{P}=0.0001 ;$ Fig. 2A). Similarly, the VAS score also had a positive correlation with EDP levels $(\mathrm{r}=0.692 ; \mathrm{P}=0.008$; Fig. 2B).

Correlation between EDP levels and IL-1 $\beta, I L-6$ or TNF- $\alpha$ levels in synovial fluid from patients with TMD. The correlation between EDP levels and IL-1 $\beta$, IL-6 or TNF- $\alpha$ levels in synovial fluid from patients with TMD was determined (Fig. 3). EDP levels had a positive correlation with IL-6 $(\mathrm{r}=0.527 ; \mathrm{P}=0.009$; Fig. 3B); however, no correlation was identified with IL-1 $\beta(\mathrm{r}=0.364 ; \mathrm{P}=0.069$; Fig. $3 \mathrm{~A})$ or TNF- $\alpha$ levels $(r=0.101 ; P=0.609 ;$ Fig. 3C).

EDPs stimulate IL-6 protein production in TMJ human synovial fibroblast cells. To determine the role of EDPs during the inflammation process in TMD, cultured human TMJ synovial fibroblast cells were treated with EDPs at a concentration of 0,25 and 50 and the levels of IL-1 $\beta$, IL-6 and TNF- $\alpha$ were measured in the culture media (Fig. 4). EDP treatment significantly increased IL-6 protein levels compared with the vehicle treated (EDPs $0 \mu \mathrm{g} / \mathrm{ml}$ ) cells $(250.01 \pm 5.09 \mathrm{pg} / \mathrm{mg}$ at $25 \mu \mathrm{g} / \mathrm{ml} ; 848.44 \pm 34.29 \mathrm{pg} / \mathrm{mg}$ at $50 \mu \mathrm{g} / \mathrm{ml}$ compared to $15.33 \pm 9.27 \mathrm{pg} / \mathrm{mg}$ for the vehicle control group, $\mathrm{P}<0.05$; Fig. 4B). No significant effect was observed on IL-1 $\beta$ and TNF- $\alpha$ protein levels (Fig. 4A and C).

EDPs induce IL- 6 and MMP-12 expression through EBP. The correlation between EDP levels and IL-6 expression observed in clinical samples was validated using in vitro inhibition. A previous study demonstrated that PKA was a mediator of elastin-induced intracellular signalling through EBP (30). Therefore, H89, a PKA inhibitor, and $\beta$-lactose, anotherinhibitor of EBP mediated signalling (30), was used to determine the role of EBP in the stimulation of IL-6 release in response to EDPs in TMJ human synovial fibroblast cells. IL-6 levels treated with EDP $(777.40 \pm 61.99 \mathrm{pg} / \mathrm{mg})$ were significantly inhibited by the H89 $(345.01 \pm 29.29 \mathrm{pg} / \mathrm{mg} ; \mathrm{P}<0.05)$ and $\beta$-lactose treatments $(539.51 \pm 30.71 \mathrm{pg} / \mathrm{mg}$; $\mathrm{P}<0.05$; Fig. $5 \mathrm{~A})$. EDPs also significantly upregulated MMP-12 expression in the cultured synovial fibroblasts $(228.47 \pm 14.48 \mathrm{pg} / \mathrm{mg}$; $\mathrm{P}<0.05)$ compared with cells treated with the vehicle control $(62.5 \pm 3.00 \mathrm{pg} / \mathrm{mg}$; Fig. 5B). The upregulation of MMP-12 was significantly inhibited following treatment with $\mathrm{H} 89(64.16 \pm 3.26 \mathrm{pg} / \mathrm{mg} ; \mathrm{P}<0.05)$ and $\beta$-lactose $(182.22 \pm 14.63 \mathrm{pg} / \mathrm{mg} ; \mathrm{P}<0.05$; Fig. 5B).

\section{Discussion}

Previous studies have demonstrated that cytokines including IL-1 $\beta(9,11,12,31,32)$, IL-6 $(9,11,12,31,33-37)$ and TNF- $\alpha(8,11,31,32,34,35)$ are associated with inflammation in synovial joints and loss of the connective tissue in TMJ. Therefore, it is possible that increased levels of these cytokines may be observed in the synovial fluid of patients with TMD. In the present study, IL-6 expression significantly correlated with the two clinical parameters investigated, duration of the TMJ disc locking and VAS score. The data of the present study was therefore consistent with a previous study which stated
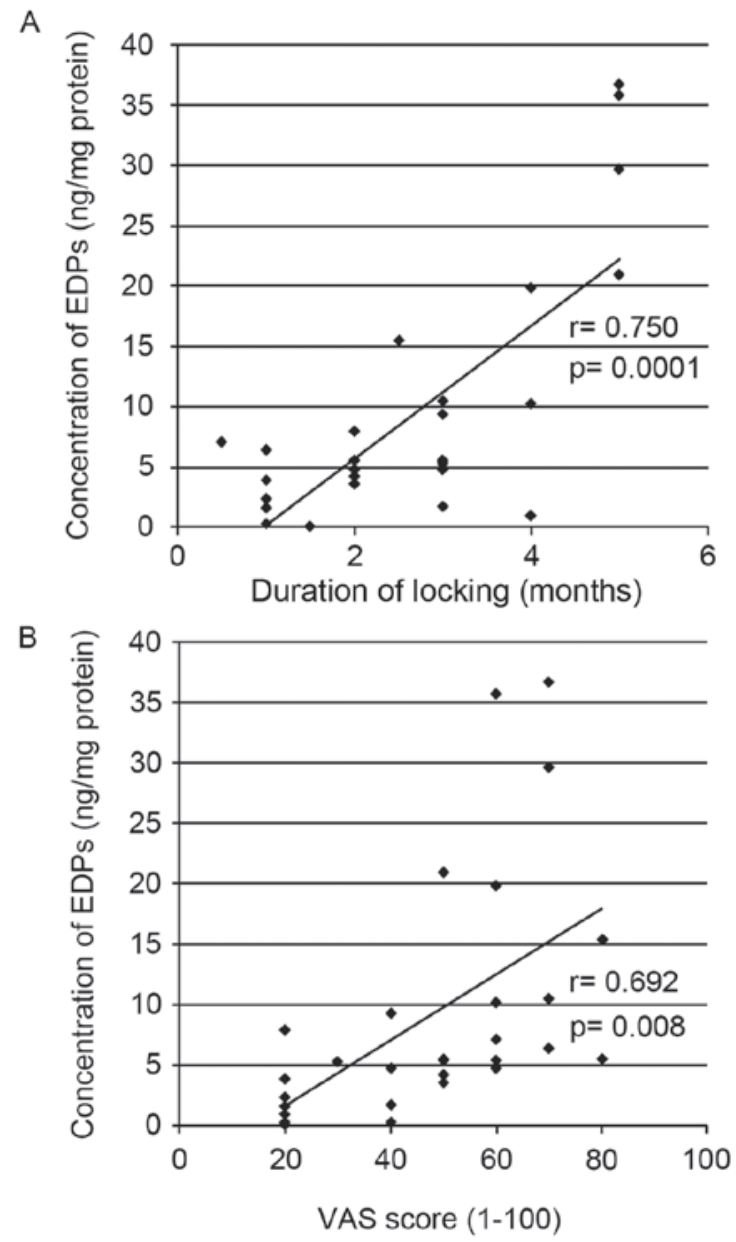

Figure 2. Concentration of EDPs in synovial fluid from patients with TMD and its correlation with duration of TMJ disc locking or VAS score. (A) Duration of TMJ disc locking for each patient was plotted against their respective EDP expression level in synovial fluid. (B) VAS score for each patient was plotted against their respective EDP expression level in synovial fluid. Each EDP expression level represents the mean of three independent experiments. EDP, elastin-derived peptides; TMD, temporomandibular dysfunction; TMJ, temporomandibular joint; VAS, visual analogue scale.

that IL-6 has a major role in the development of osteoarthritis in the TMJ (12). However, in another previous study, levels of IL-6 were determined to be comparable in the synovial fluids from patients with TMJ and OA, and healthy patients with TMJ (32). Previous studies (32,36-38) have revealed a negative correlation between frequently isolated cytokines, IL-6 (32), TNF- $\alpha(37,38)$ and IL-1 $\beta(36,38)$ and TMD. Kaneyama et al (38) suggested that no correlation was observed between the IL-1 $\beta$ or TNF- $\alpha$ levels and condyle degenerative changes due to the rapid turnover of cytokines within the joint cavity (38). However, it is difficult to elucidate the reasons behind these controversial findings, and standardization of the sampling methods, assay methods and patient cohort will be performed in future studies. The present findings may be affected by numerous clinical variables, including patient age, gender, duration and intensity of TMJ disease. Therefore, in the future, carefully designed clinical trials will need to be conducted with the aim of using the levels of pro-inflammatory cytokines to predict the extent and severity of TMJ pathology.

The pathophysiology of TMD has been previously investigated and several mechanistic studies have been reported. For 
A

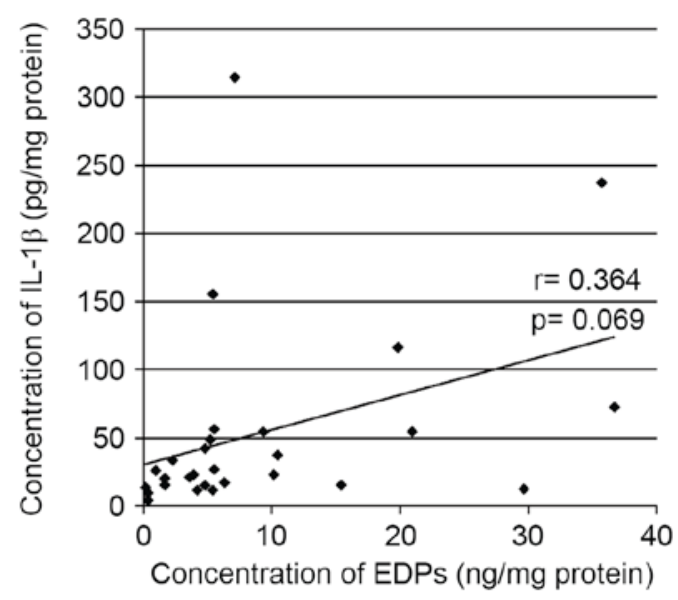

B

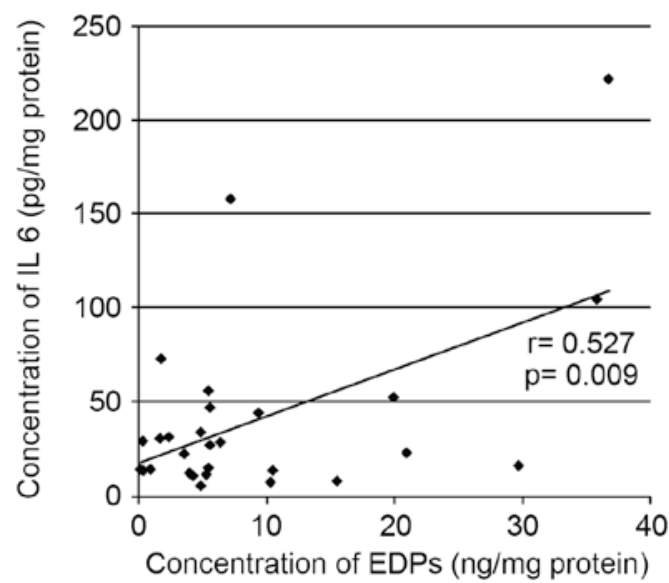

C

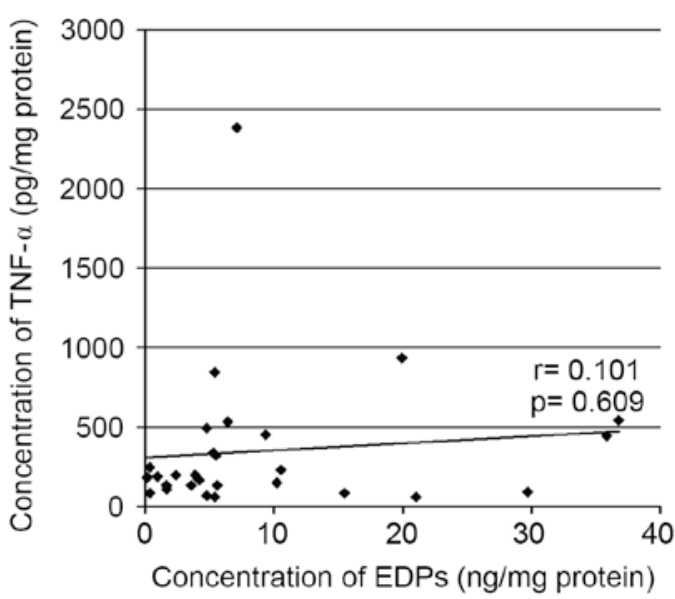

Figure 3. Concentration of EDPs and the correlation with IL-1 $\beta$, IL-6 and TNF- $\alpha$ levels in synovial fluid from patients with temporomandibular dysfunction. Individual patient levels of EDPs in synovial fluid were plotted against the patients respective (A) IL-1 $\beta$, (B) IL-6 or (C) TNF- $\alpha$ protein levels in synovial fluid. Each protein level represents the mean of three independent experiments. IL-1 $\beta$, interleukin-1 $\beta$; IL-6, interleukin-6; TNF- $\alpha$, tumor necrosis factor- $\alpha$; EDP, elastin-derived peptides.

example, loss of disc elastic fibres was observed following induction of anterior disc displacement or disc perforation $(39,40)$. It has also been reported that the abundance of elastic fibres in the bilaminar zone was reduced in patients with internal disc derangement $(23,26,27)$. A previous study demonstrated that the presence and distribution of newly formed elastic fibres, was associated with the degree of disc tissue damage to, or the complete absence of collagen bundles (41).
A

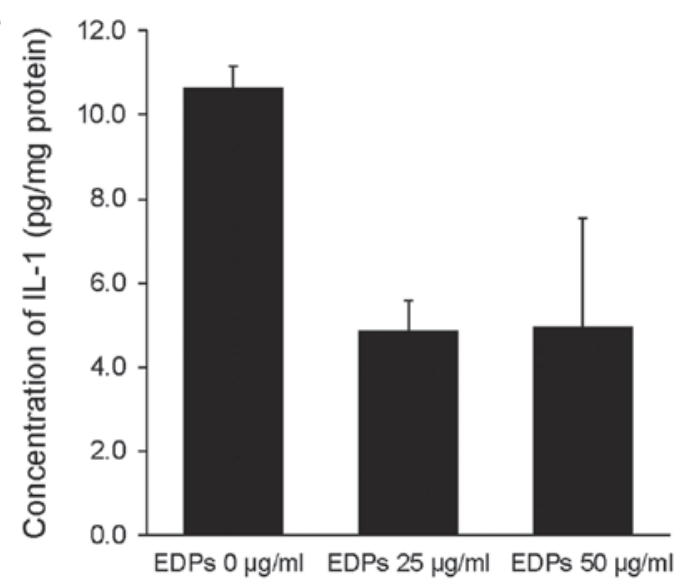

$\mathrm{B}$

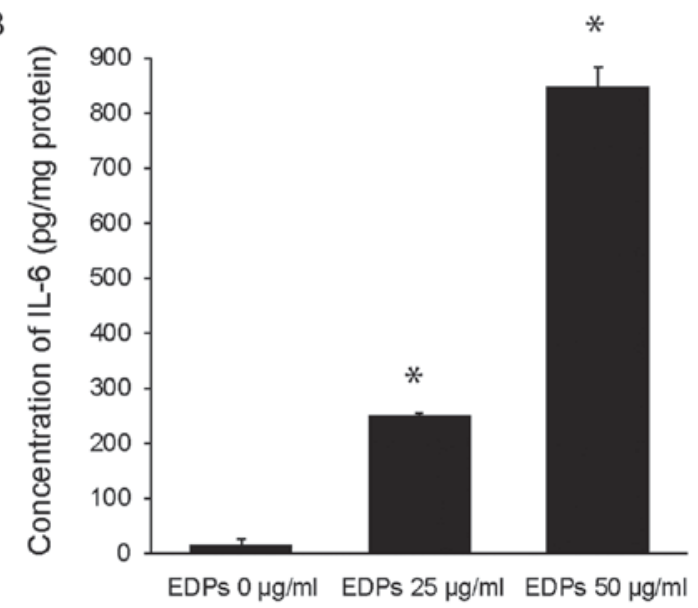

C

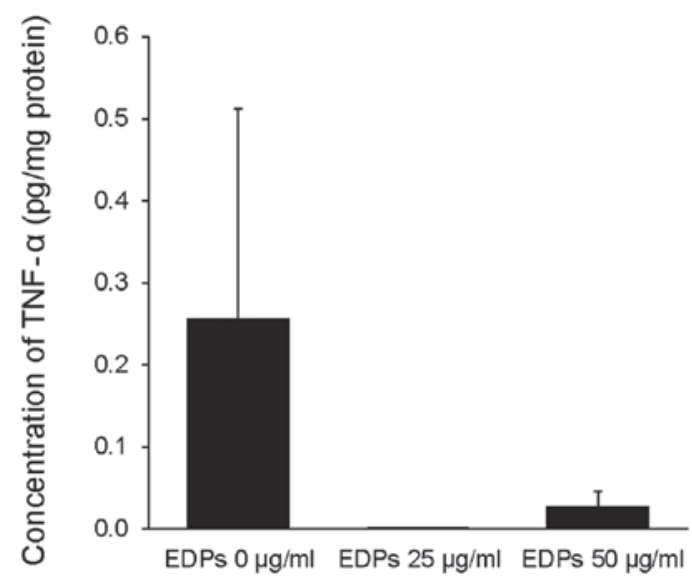

Figure 4. EDPs stimulate IL-6 protein expression in TMJ human synovial fibroblast cells. Expression of (A) IL-1 $\beta$, (B) IL-6 or (C) TNF- $\alpha$ in cultured human TMJ synovial fibroblast cells treated with EDPs at 0,25 , and $50 \mu \mathrm{g} / \mathrm{ml}$ concentration. Data are presented as the mean \pm standard error of the mean from triplicate experiments. ${ }^{*} \mathrm{P}<0.05$. EDP, elastin-derived peptides; TMJ, temporomandibular joint; IL-1 $\beta$, interleukin-1 $\beta$; IL-6, interleukin-6; TNF- $\alpha$, tumor necrosis factor- $\alpha$.

Previous studies (7-13) have focused on examining pro-inflammatory cytokines, to the best of our knowledge the present study was the first to determine the quantity of EDPs present in synovial fluid. In current study determined the concentration of EDPs in the synovial fluid of patients with TMD and revealed that the levels of EDPs were significantly correlated with VAS score or duration of TMJ disc locking as well as IL-6 expression in the synovial fluid of patients with 

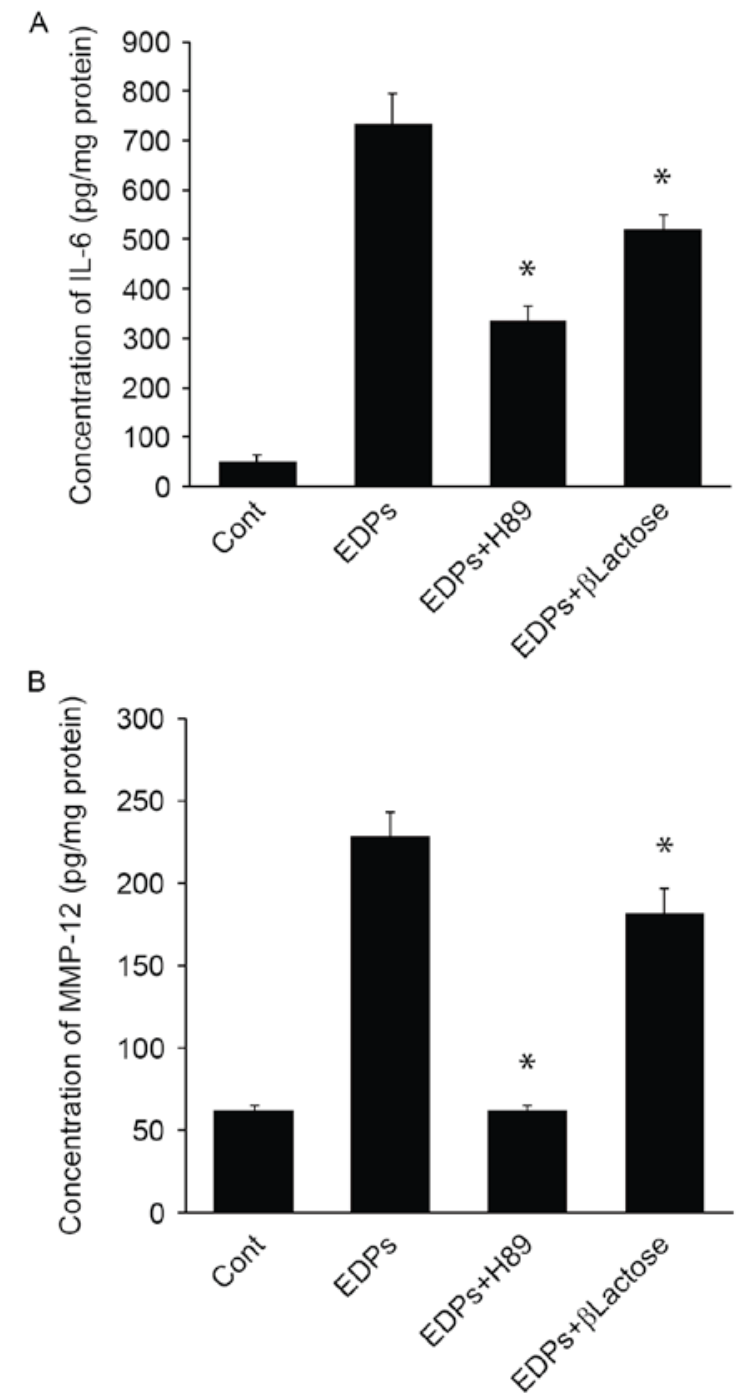

Figure 5. EDPs induce IL-6 and MMP-12 expression through elastin binding protein. Expression levels of (A) IL-6 and (B) MMP-12 in cultured human temporomandibular joint synovial fibroblast cells treated with EDPs alone or EDPs in the presence of H89, $\beta$-lactose, or vehicle control. Data are presented as the mean \pm standard error of the mean from triplicate experiments. ${ }^{*} \mathrm{P}<0.05$. EDP, elastin-derived peptides; IL-6, interleukin-6; MMP-12, matrix metalloproteinase 12; H89, protein kinase A inhibitor.

TMD. The biological role of elastin, as the fundamental unit of an elastic fibre, was originally believed to be restricted only to mechanical maintenance of tissue architecture. This simple view of elastin has now evolved as EDPs have been revealed to be biologically active in a range of normal and transformed cells $(42,43)$. However, despite these new insights, the role for EDPs in the pathophysiology of TMD, to the best of our knowledge, has not been previously investigated.

In elastin-rich tissues such as arteries, lungs and skin, inflammation is concomitant with elastolysis, leading to the generation of EDPs $(42,44,45)$. In these cases, a direct association between inflammation and EDP levels has been established. The present study determined that EDPs may act selectively on human TMJ synovial cells to stimulate IL-6 production, with no significant effect on IL-1 $\beta$ or TNF- $\alpha$ production. IL-6 is produced at the site of inflammation and has a key role in the acute phase response (46). Following the onset of the inflammatory response, IL- 6 secreted by synovial cells in the TMJ may act as a chemoattractant for other cell types important to tissue degradation. In a previous study, stimulation of cartilage explants with IL-6 potentiated proteoglycan (aggrecan) catabolism in articular cartilage. This catabolism was associated with aggrecanase activity (47). In this regard, upregulation of IL-6 is critical for the progression of arthritic diseases. Under inflammatory conditions, changes in the levels of polarized Th1 and Th2 cells may also to be important $(48,49)$. Therefore, the expression levels of a Th1 cytokine (TNF- $\alpha$ ) and a Th2 cytokine (IL-6) were examined in EDP-treated TMJ synovial cells. The expression of IL-6; however, not TNF- $\alpha$, was increased by EDPs suggesting that EDPs stimulate a Th2 cellular response. Characterization of Th1 and Th2 response has been previously performed using synovial tissue samples obtained from a patient with erosive rheumatoid arthritis (50). The synovial tissue sample used in the present study had an unusual Th2 dominant pattern. A previous study has demonstrated that IL- 6 deficient mice had reduced Th2 responses and increased arthritis (51). These findings demonstrated that a predominantly $\mathrm{Th} 2$ response may be associated with arthritis.

EDPs may act via EBP, which is located on the membrane of fibroblasts, granulocytes, lymphocytes, monocytes and cancer cells (52). H89 inhibition of PKA was used to determine the role of PKA as a key intracellular signalling mediator downstream of EBP (30). EBP is inhibited by $\beta$-lactose (30); however, $\alpha$-lactose is only a partial inhibitor due to its partial conversion to $\beta$-lactose by anomerization (53). The present study revealed that $\mathrm{H} 89$ and $\beta$-lactose inhibited EDP stimulated expression of IL- 6 in TMJ synovial cells. These findings suggest that the induction of IL-6 expression by EDPs involved the EBP and a PKA signalling cascades. MMP-12 is a member of a group of enzymes that are able to degrade elastin. The present study revealed that MMP-12 is secreted from EDP-treated TMJ synovial cells and that, similarly to IL-6, this process was also inhibited by $\mathrm{H} 89$ and $\beta$-lactose. Therefore, from these findings a model for the initiation of the inflammatory process in the TMJ may be proposed. Harmful mechanical stimuli, and in particular pressure, may lead to tissue damage in the TMJ. EDPs are then generated, as endogenous danger signals and induce a pro-inflammatory cascade by activating EBP signalling. Subsequently, pro-inflammatory mediators, such as IL-6 and MMP-12 are upregulated and trigger further tissue damage leading to increased EDP levels. Therefore, a positive feedback loop is established and may lead to chronic inflammation of the TMJ. Therefore, significantly higher levels of a combination of EDPs and IL-6 in the synovial fluid of patients with TMJ may be indicators of the pathological condition of the joint.

\section{Acknowledgements}

The authors would like to thank the members of the Department of Oral and Maxillofacial Surgery of Kanazawa University for their helpful suggestions and assistance and Elsevier Language Editing Services for assistance with language editing. The present study was supported by grants-in-aid for Scientific Research from the Ministry of Education, Science, Sports and Culture, Japan (grant no. 15 H05042 to Dr Shuichi Kawashiri and grant no. 25462882 to Dr Hiroyuki Nakamura). 


\section{References}

1. Carls FR, von Hochstetter A, Makek M and Engelke W: Diagnostic accuracy of TMJ arthroscopy in correlation to histological findings. J Craniomaxillofac Surg 23: 75-80, 1995.

2. Dijkgraaf LC, Liem RS and de Bont LG: Synovial membrane involvement in osteoarthritic temporomandibular joints: A light microscopic study. Oral Surg Oral Med Oral Pathol Oral Radiol Endod 83: 373-386, 1997.

3. Gynther GW, Holmlund AB, Reinholt FP and Lindblad S: Temporomandibular joint involvement in generalized osteoarthritis and rheumatoid arthritis: A clinical, arthroscopic, histologic, and immunohistochemical study. Int J Oral Maxillofac Surg 26: 10-16, 1997.

4. Gynther GW, Dijkgraaf LC, Reinholt FP, Holmlund AB, Liem RS and de Bont LG: Synovial inflammation in arthroscopically obtained biopsy specimens from the temporomandibular joint: A review of the literature and a proposed histologic grading system. J Oral Maxillofac Surg 56: 1281-1287, 1998.

5. Kardel R, Ulfgren AK, Reinholt FP and Holmlund A: Inflammatory cell and cytokine patterns in patients with painful clicking and osteoarthritis in the temporomandibular joint. Int $\mathbf{J}$ Oral Maxillofac Surg 32: 390-396, 2003.

6. Satoh K, Ogura N, Akutsu M, Kuboyama N, Kuyama K, Yamamoto $\mathrm{H}$ and Kondoh T: Expression of cyclooxygenase-1 and -2 in IL-1beta-induced synovitis of the temporomandibular joint. J Oral Pathol Med 38: 584-590, 2009.

7. Shafer DM, Assael L, White LB and Rossomando EF: Tumor necrosis factor-alpha as a biochemical marker of pain and outcome in temporomandibular joints with internal derangements. J Oral Maxillofac Surg 52: 786-792, 1994.

8. Fu K, Ma X, Zhang Z and Chen W: Tumor necrosis factor in synovial fluid of patients with temporomandibular disorders. J Oral Maxillofac Surg 53: 424-426, 1995.

9. Kubota E, Kubota T, Matsumoto J, Shibata T and Murakami KI: Synovial fluid cytokines and proteinases as markers of temporomandibular joint disease. J Oral Maxillofac Surg 56: 192-198, 1998.

10. Sandler NA, Buckley MJ, Cillo JE and Braun TW: Correlation of inflammatory cytokines with arthroscopic findings in patients with temporomandibular joint internal derangements. J Oral Maxillofac Surg 56: 534-544, 1998.

11. Takahashi T, Kondoh T, Fukuda M, Yamazaki Y, Toyosaki T and Suzuki R: Proinflammatory cytokines detectable in synovial fluids from patients with temporomandibular disorders. Oral Surg Oral Med Oral Pathol Oral Radiol Endod 85: 135-141, 1998

12. Kaneyama K, Segami N, Nishimura M, Suzuki T and Sato J: Importance of proinflammatory cytokines in synovial fluid from 121 joints with temporomandibular disorders. Br J Oral Maxillofac Surg 40: 418-423, 2002.

13. Nishimura M, Segami N, Kaneyama K, Sato J and Fujimura K Comparison of cy tokine level in synovial fluid between successful and unsuccessful cases in arthrocentesis of the temporomandibular joint. J Oral Maxillofac Surg 62: 284-288, 2004.

14. Muiznieks LD, Weiss AS and Keeley FW: Structural disorder and dynamics of elastin. Biochem Cell Biol 88: 239-250, 2010.

15. Hornebeck W and Robert L: Elastase-like enzymes in aortas and human breast carcinomas: Quantitative variations with age and pathology. Adv Exp Med Biol 79: 145-164, 1977.

16. Hornebeck W, Emonard H, Monboisse JC and Bellon G Matrix-directed regulation of pericellular proteolysis and tumor progression. Semin Cancer Biol 12: 231-241, 2002.

17. Gayral S, Garnotel R, Castaing-Berthou A, Blaise S, Fougerat A, Berge E, Montheil A, Malet N, Wymann MP, Maurice P, et al: Elastin-derived peptides potentiate atherosclerosis through the immune Neu1-PI3K $\gamma$ pathway. Cardiovasc Res 102: 118-127, 2014

18. Scandolera A, Odoul L, Salesse S, Guillot A, Blaise S, Kawecki C, Maurice P, El Btaouri H, Romier-Crouzet B, Martiny L, et al: The elastin receptor complex: A unique matricellular receptor with high anti-tumoral potential. Front Pharmacol 7: 32, 2016.

19. Duca L, Floquet N, Alix AJ, Haye B and Debelle L: Elastin as a matrikine. Crit Rev Oncol Hematol 49: 235-244, 2004.

20. Bravetti P, Membre H, El Haddioui A, Gérard H, Fyard JP, Mahler P and Gaudy JF: Histological study of the human temporo-mandibular joint and its surrounding muscles. Surg Radiol Anat 26: 371-378, 2004

21. Scapino RP: Histopathology associated with malposition of the human temporomandibular joint disc. Oral Surg Oral Med Oral Pathol 55: 382-397, 1983
22. Benigno MI, Azeredo RA, Lemos JL, König Júnior B and Liberti EA: The structure of the bilaminar zone in the human temporomandibular joint: A light and scanning electron microscopy study in young and elderly subjects. J Oral Rehabil 28: 113-119, 2001.

23. Hall MB, Brown RW and Baughman RA: Histologic appearance of the bilaminar zone in internal derangement of the temporomandibular joint. Oral Surg Oral Med Oral Pathol 58: 375-381, 1984.

24. Minarelli AM and Liberti EA: A microscopic survey of the human temporomandibular joint disc. J Oral Rehabil 24 $835-840,1997$.

25. Thilander B, Carlsson GE and Ingervall B: Postnatal development of the human temporomandibular joint I. A histological study. Acta Odontol Scand 34: 117-126, 1976.

26. Toller PA: Ultrastructure of the condylar articular surface in severe mandibular pain-dysfunction syndrome. Int J Oral Surg 6: 297-312, 1977.

27. Pereira FJ, Lundh H, Eriksson L and Westesson PL: Microscopic changes in the retrodiscal tissues of painful temporomandibular joints. J Oral Maxillofac Surg 54: 461-469, 1996.

28. Alstergren P, Kopp S and Theodorsson E: Synovial fluid sampling from the temporomandibular joint: Sample quality criteria and levels of interleukin-1 beta and serotonin. Acta Odontol Scand 57: 16-22, 1999.

29. Skeie JM, Hernandez J, Hinek A and Mullins RF: Molecular responses of choroidal endothelial cells to elastin derived peptides through the elastin-binding protein (GLB1). Matrix Biol 31: 113-119, 2012.

30. Almine JF, Wise SG, Hiob M, Singh NK, Tiwari KK, Vali S, Abbasi $\mathrm{T}$ and Weiss AS: Elastin sequences trigger transient proinflammatory responses by human dermal fibroblasts. FASEB J 27: 3455-3465, 2013.

31. Kaneyama K, Segami N, Sun W, Sato J and Fujimura K: Analysis of tumor necrosis factor-alpha, interleukin-6, interleukin-1beta, soluble tumor necrosis factor receptors I and II, interleukin-6 soluble receptor, interleukin-1 soluble receptor type II, interleukin-1 receptor antagonist, and protein in the synovial fluid of patients with temporomandibular joint disorders. Oral Surg Oral Med Oral Pathol Oral Radiol Endod 99: 276-284, 2005.

32. Vernal R, Velásquez E, Gamonal J, Garcia-Sanz JA, Silva A and Sanz M: Expression of proinflammatory cytokines in osteoarthritis of the temporomandibular joint. Arch Oral Biol 53: 910-915, 2008.

33. Fu K, Ma X, Zhang Z, Pang X and Chen W: Interleukin-6 in synovial fluid and HLA-DR expression in synovium from patients with temporomandibular disorders. J Orofac Pain 9: 131-137, 1995.

34. Kaneyama K, Segami N, Sato J, Nishimura M and Yoshimura H: Interleukin-6 family of cytokines as biochemical markers of osseous changes in the temporomandibular joint disorders. Br J Oral Maxillofac Surg 42: 246-250, 2004.

35. Lee JK, Cho YS and Song SI: Relationship of synovial tumor necrosis factor alpha and interleukin 6 to temporomandibular disorder. J Oral Maxillofac Surg 68: 1064-1068, 2010.

36. Shinoda C and Takaku S: Interleukin-1 beta, interleukin-6, and tissue inhibitor of metalloproteinase-1 in the synovial fluid of the temporomandibular joint with respect to cartilage destruction. Oral Dis 6: 383-390, 2000.

37. Wake M, Hamada Y, Kumagai K, Tanaka N, Ikeda Y, Nakatani Y, Suzuki R and Fukui N: Up-regulation of interleukin- 6 and vascular endothelial growth factor-A in the synovial fluid of temporomandibular joints affected by synovial chondromatosis. Br J Oral Maxillofac Surg 51: 164-169, 2013.

38. Kaneyama K, Segami N, Nishimura M, Sato J, Suzuki T and Fujimura K: Osteoclastogenesis inhibitory factor/osteoprotegerin in synovial fluid from patients with temporomandibular disorders. Int J Oral Maxillofac Surg 32: 404-407, 2003.

39. Sato S, Goto S, Kamakura S and Motegi K: Morphologic changes in the elastic fibers of the temporomandibular joint after experimental disc perforation in the rabbit. J Oral Maxillofac Surg 56: 753-759, 1998.

40. Ali AM, Sharawy M, O'Dell NL and al-Behery G: Morphological alterations in the elastic fibers of the rabbit craniomandibular joint following experimentally induced anterior disk displacement. Acta Anat (Basel) 147: 159-167, 1993.

41. Leonardi R, Villari L, Bernasconi $\mathrm{G}$ and Caltabiano M: Histochemical study of the elastic fibers in pathologic human temporomandibular joint discs. J Oral Maxillofac Surg 59: 1186-1192, 2001. 
42. Duca L, Lambert E, Debret R, Rothhut B, Blanchevoye C, Delacoux F, Hornebeck W, Martiny L and Debelle L: Elastin peptides activate extracellular signal-regulated kinase $1 / 2$ via a Ras-independent mechanism requiring both p110gamma/Raf-1 and protein kinase A/B-Raf signaling in human skin fibroblasts. Mol Pharmacol 67: 1315-1324, 2005.

43. Simionescu A, Philips K and Vyavahare N: Elastin-derived peptides and TGF-betal induce osteogenic responses in smooth muscle cells. Biochem Biophys Res Commun 334: 524-532, 2005.

44. Houghton AM, Quintero PA, Perkins DL, Kobayashi DK, Kelley DG, Marconcini LA, Mecham RP, Senior RM and Shapiro SD: Elastin fragments drive disease progression in a murine model of emphysema. J Clin Invest 116: 753-759, 2006.

45. Robinet A, Fahem A, Cauchard JH, Huet E, Vincent L, Lorimier S, Antonicelli F, Soria C, Crepin M, Hornebeck W and Bellon G: Elastin-derived peptides enhance angiogenesis by promoting endothelial cell migration and tubulogenesis through upregulation of MT1-MMP. J Cell Sci 118: 343-356, 2005.

46. Gabay C: Interleukin-6 and chronic inflammation. Arthritis Res Ther 8 (Suppl 2): S3, 2006.

47. Flannery CR, Little CB, Hughes CE, Curtis CL, Caterson B and Jones SA: IL-6 and its soluble receptor augment aggrecanase-mediated proteoglycan catabolism in articular cartilage. Matrix Biol 19: 549-553, 2000.
48. Romagnani S: Lymphokine production by human $\mathrm{T}$ cells in disease states. Annu Rev Immunol 12: 227-257, 1994.

49. Abbas AK, Murphy KM and Sher A: Functional diversity of helper T lymphocytes. Nature 383: 787-793, 1996.

50. Aarvak T, Chabaud M, Thoen J, Miossec P and Natvig JB Changes in the Th1 or Th2 cytokine dominance in the synovium of rheumatoid arthritis (RA): A kinetic study of the Th subsets in one unusual RA patient. Rheumatology (Oxford) 39: 513-522, 2000.

51. Anguita J, Rincón M, Samanta S, Barthold SW, Flavell RA and Fikrig E: Borrelia burgdorferi-infected, interleukin-6-deficient mice have decreased Th2 responses and increased lyme arthritis. J Infect Dis 178: 1512-1515, 1998.

52. Helbig G and Krzemień S: Clinical significance of elastin turnover-focus on diseases affecting elastic fibres. Wiad Lek 57: 360-363, 2004.

53. Jawad R, Elleman C, Vermeer L, Drake AF, Woodhead B, Martin GP and Royall PG: The measurement of the $\beta / \alpha$ anomer composition within amorphous lactose prepared by spray and freeze drying using a simple (1)H-NMR method. Pharm Res 29: 511-524, 2012. 